\title{
The influence of art and art therapy on people
}

\author{
Azimova Fotima ${ }^{1}$ \\ ${ }^{1}$ Lecturer at Yeoju Technical Institute, Tashkent, Uzbekistan \\ Email:dunyoguzali@mail.ru
}

\begin{abstract}
The article is devoted to studying of influence of art on people and possibilities of application of art therapy in life. The main purpose of art therapy is defined as harmonization of the person's inner state, help people find the optimal state of balance conducive to the active continuation of life. The methods of art therapy influence on the formation of creative abilities of people. The article analyzes study and application of art therapy methods as methods of personality development. The most appropriate methods of art therapy that are used to reveal creative potential of people are analyzed. Art therapy can be used to prevent and correct negative psychological states in a child and an adult (fear, fatigue, aggressiveness, irritability, etc.). The article gives the description of the main methods of art therapy.
\end{abstract}

Key words: art, art therapy, self-expression, drawing, music, color therapy.

\section{INTRODUCTION}

Our inner world is filled with images and notions that do not leave us indifferent that worry and hurt, through which there is emotional communication between people, and our consciousness interacts with the unconscious. The deeper and more intense it happens, the more works of art that are created to tell people in the language of images about the sufferings and joys of spiritual life and find respond in the soul of a viewer and a listener.

The poetic language of images of dreams and fantasies, feelings and experiences is unfamiliar to the mind of a rationally thinking man of a big city living at a great speed. But it is very important, as with the help of art we try to adapt to changes in our lives, trying to find meaning in what we do, feel, think, the meaning of how we live. Thus, art has an adaptive function and plays a very important regulatory role in the organization of our lives.

One of the most important tasks of psychotherapy is to restore the broken links between feelings and mind, to develop an integral personality, to discover personal meanings through creativity. Probably, art therapy, which uses the language of art for this purpose, is the best way to do it.

Art therapy is a direction in psychotherapy, rehabilitation and psycho-correction based on exercises of patients (clients) with creativity and arts. Art therapy is a therapeutic technique rooted in the idea that creative expression can foster healing and mental well-being $[2,254]$. Art therapy can be considered as one of the directions of psychotherapy with such tools as music therapy, drama therapy and dance therapy.

At the moment, art therapy is considered to act a therapeutic visual art of the client, involving the relationship between the specialist and the author of the artwork and work itself. Creation of visual images is seen as an important way of interpersonal communication and as a form of cognitive activity of the client, allowing him to show the early or topical "here-and-now" experiences that are difficult to formulate in words.

Despite the close connection to therapeutic activity, art therapy in many cases acquires a predominantly psycho preventive, socializing and developing direction. During the course of his life, art therapy has likened the achievements of psychological science and practice, theoretical studies and techniques of different currents of psychotherapy, experience and strategies of fine arts, methods of pedagogy, separate concepts of the theory of culture, sociology and other sciences. Art therapy continues to actively develop at present time, studying new areas of practical implementation and enriching itself with ideas by combining them with other scientific disciplines.

The main objectives of this article are to consider the theoretical directions of art therapy; to analyze art therapy; to consider its goals and approaches; to consider different directions in art therapy. 


\section{HISTORY OF ART THERAPY}

Art therapy is a private form of therapy related to creativity and mainly to the so-called visual arts (painting, sculpture, graphics, photography, as well as their various combinations with other creative activities). In addition to art therapy, the group of different therapy options for creativity also includes music therapy, drama therapy, dance and movement therapy, etc.

The term "art therapy" first began to be used in English countries around the 40s of the twentieth century. In 1938 it was introduced by Adrian Hill. Doctors noted that individuals suffering from mental illness often expressed themselves in drawings and other artworks, which led many to explore the use of art as a healing strategy $[1,288]$. The founders of art therapy relied on Freud's ideas that a person's inner self is expressed in a visual form every time he spontaneously draws and sculpts, as well as on Jung's ideas about individual and universal symbols. The main figure in the art therapeutic course is not the patient (as a sick person), but a person who strives for self-development and expansion of his own possibilities.

A new rise in interest in creative therapy, in particular, in art therapy, begins around the mid-twentieth century, when it has become increasingly used as a type of therapy in the employment of a greater extent in psychiatric and general hospitals. Their key objective was to provide patients with a relatively free opportunity to engage in simple visual activities in which they could be distracted from the negative experiences associated with the disease.

\section{THE ESSENCE OF ART THERAPY, ITS GOALS AND CHALLENGES}

The appeal of art therapy mainly for modern man is that this method mainly uses non-verbal way of communication and self-expression. The right hemisphere of the brain is actively involved in the creative process. The current civilization mainly uses the verbal system of communication and the left "logical" hemisphere. Natural, harmonious human development requires equal development of both hemispheres and normal interhemispheric interaction. Moreover, there are types of human activity that require exactly the work of the right hemisphere - creativity, cultural education, and intuition, family building, raising children and, naturally, romanticism in love relations. Art therapy refers to internal, self-healing resources of a person, which are closely related to his or her creative abilities. Distinctive feature of a person is his or her ability and at the same time need to reflect his or her inner world. This ability makes it possible to actively work through the information that comes from outside. As a result, various adaptive mechanisms are formed in an individual's psyche. They allow a person to better adapt to life, to be more successful in an ever-changing world. In the process of interaction with the world a person seeks to realize himself as a person, to find his role in life, to leave a "trace". This "trace" remains not only in the form of economic activity, but also in the products of his active mental activity. Creativity and art can be considered one of its most vivid forms of manifestation. Creativity and art are the result of processes of information processing in interaction with the surrounding world. The personality will develop harmoniously if these processes, in general, are constructive.

The method of art therapy is often used in rehabilitation of people with special developmental needs and in work with children. Children with developmental disabilities have difficulties in adequately perceiving the world. Their perception of the holistic picture of the world is impaired. A child may perceive the world as a chaotic, disparate set of elements. As a result, he is unable to find his place in life, to become a full member of society. Later, the nature of interaction with environment becomes destructive in general. This situation can be influenced in different ways. The most natural is the creation of conditions for human development with the help of natural elements included in life of a person which harmonizes his or her activities - decorating his or her home, taking care of pets, doing creative work and needlework. In addition, man is part of nature and specially organized interaction with nature should probably have a positive result. Creative work usually reflects ways of interacting with nature. Art therapy enables a child to express his or her emotions and feelings by sculpting, drawing, constructing from natural materials. Experiencing images, a person acquires their integrity, uniqueness and individuality. It is also possible to apply other forms of art - theatrical performances, improvisations, literary creativity. Thus, the following goals are achieved:

* The expression of emotions and feelings related to the experiences of any problems;

* The active search for new forms of interaction with the world;

* Confirmation of uniqueness, specificity and significance of a personality;

* And, as an effect of the previous three, increased adaptability (flexibility) in an ever-changing world.

The art therapist pursues these goals by working with both children and adults. The child cannot yet express what he or she is concerned about. They can express their fears with simple sentences, for example: "I'm scared, in the dark someone might steal me." When a child is asked who it may be, the child may not 
answer, but will try to draw or give figurative meaning to his fear. Art therapy is the gentlest method of work in contact with serious problems. A child cannot recognize his or her problems and talk about them, but can express himself or herself with the movement of the body. Art therapy can also relieve mental tension.

Some mental and physical impairments make the child passive, and the child's interests become narrow. The desire to actively interact with the world is reduced. As a result, the ability to adapt decreases as well. The child becomes reserved. He thinks he cannot find a way out of this situation. Art therapy can break this circle. In the process of creative work, the child invents new ways to express his emotions. And unconsciously finds new ways to communicate with the outside world. In this way, the lost abilities are restored.

It is very important that the child feels his success doing creative work. If he sees that he is successful in displaying and expressing his emotions, creating unique ornaments, drawings, it becomes easier for him to communicate, and interaction with the world becomes more constructive. Success in art is unconsciously transferred to ordinary life.

From materials of everyday life (branches, sand, leaves, clay, scraps of paper, stones) it is possible to create beautiful products. It is also possible to solve a difficult psychological problem - to look at it from a different angle. The human psyche acquires flexibility. This quality allows you to be more adaptive. This is the purpose of rehabilitation. Art therapy makes this process fun, interesting, effective and individual.

Subsequently, adults and children undergoing art therapy can find a hobby, learn a new kind of applied art. The new hobby allows paying more attention to yourself. It promotes a more harmonious relationship between parents and child.

In art therapy, both group work and individual forms are used. The brightest effect is given by work in a group. For example, it is proposed to create a common work, the creation of individual works in the group, as well as the creation of a common work. Each participant puts something different into this work. Patients may take with them works made of paper, compositions of natural material and show them to their relatives and friends, trying to teach them what they have learned.

Modern scientific art therapy, not surprisingly, with all its diversity of connections with cultural facts is closest to the "primitive" ancient art. Like art therapy, it is based on spontaneous self-expression and ignores all aesthetic criteria in evaluating its results and the professionalism of the creator. Because, the process of creation is more important than the result.

Archaic forms of art have survived the longest in folk art. Its direct-acting nature and naivety, as well as its reliance on the symbolic language of the collective unconscious during the period of "high", academic art, were the source of spiritual health for many people. The simplicity of patterns, rhythmic ornamentation soothes. Primitive ornament - a sequence of crosses during embroidery or carving on the figure - a kind of meditation, bringing to a state of satisfaction and peace.

Many "primitive" drawings and products, in their appearance, resemble the creations of children, which is also associated with experiences that are rather positive for the person.

In art therapy there are two main approaches:

1) Art has healing properties, artistic creativity allows to express and relive spiritual conflicts, it is a means of enriching personal experience, art therapy is seen as a means of developing the creative potential of the individual, the main mechanisms - sublimation and transformation. The leader encourages the group members to trust their own perception and to study their creations both independently and with the help of other group members.

2) The therapeutic goals take the first place, while creative goals are secondary; art therapy acts as a supplement to other therapeutic methods, expressing the essence of one's inner world in a visual form, a person moves towards their awareness time after time, the main mechanism is transfer. The leading groups are encouraged to freely associate the members of the groups and their attempts to reveal the meaning of their own works independently. Some activities consist of joint group work, such as creating murals by the group and creating a common group image.

The main purpose of art therapy is self-discovery, expanding one's own experience, self-expression, internal integration of a person (in its various aspects and components) and integration with external reality (social, cultural, ethnic). In art therapy spontaneous creativity is a kind of work of imagination, rather than an expression of artistic talent.

Visual creativity is a bridge between the world of fantasy and reality. It includes parts of both, allowing you to create a synthesis that neither adult nor child cannot form without the help of artistic means.

In art therapy, an important concept is sublimation the expression of attractions and unconscious instincts (sometimes destructive) by transforming them into works of art. Art can "direct them in a different direction" and express feelings such as: anger, pain, anxiety, fear. 
Advantages of the art therapeutic method:

- Gives an opportunity to express aggressive feelings in a socially acceptable manner. Painting or molding are safe ways to relieve tension;

- Accelerates the progress of the therapy. Internal experiences and subconscious conflicts are more freely expressed through visual images than through conversation (verbal psychotherapy). Nonverbal forms of communication are more likely to avoid conscious censorship;

- Provides grounds for diagnostic work and interpretation during therapy. Creative products cannot be denied by the patient due to their reality. The style of the artwork and its content provide the therapist with tremendous information; moreover, the author himself can contribute to the interpretation of his own creations;

- Gives the opportunity to work with feelings and thoughts that seem overwhelming (death, loss, violence and trauma, internal conflicts, fears, memories from childhood, dreams). Sometimes a nonverbal remedy turns out to be the only tool that cuts and clarifies active emotions and beliefs;

- Helps to strengthen therapeutic relationships. Common elements in the artistic creation of group members can accelerate the development of positive feelings and empathy;

- Contributes to a sense of internal order and control;

- Develops and strengthens attention to feelings;

- Improves the sense of personal value, increases artistic competence. The final product of art therapy is satisfaction resulting from the discovery and development of hidden skills.

Psychotherapeutic influences in art therapy (something that has a healing effect):

- The artistic factor of expression is the embodiment of feelings, thoughts and needs of the client in his work, experience of interaction with all kinds of artistic materials and artistic image;

- The psychotherapeutic factor of mutual relations - dynamics of relations of the client-therapist-group (transfer and counter transfer), influence of personal experience;

- Verbal factor of feedback and interpretation - transformation, transfer of material (process and result of creative work) from emotional level to the level of understanding, formation of meanings.

- The art therapy group provides the group with the necessary material and shows maximum flexibility to stimulate artistic creativity. The room should provide space for movement and lively games. The role of the leader is to promote creativity. The members of the group are instructed to fully immerse themselves in their feelings and not to care about the artistic creativity of their creations.

If we talk about types of art therapy, we can distinguish among drawing therapy, music therapy, dance and motor therapy, drama therapy, fairytale therapy, bibliotherapy, sand therapy, game therapy, color therapy, phototherapy, puppet therapy, origami. Now there are more and more new directions, which stand at the junction of art therapy and other areas of psychotherapy: art therapy, phototherapy, body art, landscape therapy, work on collages, etc. Most popular types of art therapy include drawing, music therapy, dance and motor therapy, bibliotherapy, color therapy.

Drawing therapy is one of the most popular types of art used in art therapy. Drawing allows to reveal problems or fantasies which for any reason are difficult to discuss verbally; creates conditions for experimenting with visual and kinesthetic sensations; promotes development of aesthetic experience, creative expression, improvement of artistic abilities in general. Drawing helps to develop a sense of internal control. Drawing is the safest way to defuse destructive and self-destructive tendencies.

Music therapy is a psychotherapeutic method based on the healing effect of music on the psychological state of a person. A distinction is made between passive and active forms of music therapy. In passive music therapy, patients are offered to listen to various music pieces corresponding to their psychological state and the course of treatment. The aim in this case is a certain emotional experience, which should contribute to the response of certain problems and the achievement of new meanings. In active music therapy patients themselves participate in the performance of musical works (in a choir or music orchestra), using both ordinary musical instruments and unusual ones, such as their own body (claps, tapping, etc.).

Dance therapy is a psychotherapy method in which the body is a tool and movement is a process that helps people to experience, recognize and express their feelings and conflicts. In addition to movement, this type of therapy uses concepts such as weight, space and time. With dance and motor therapy, the patient can use movement to express themselves more fully and to maintain their authenticity in contact with others. 
Bibliotherapy is a very attractive therapy option because it is simple and effective enough to help people facing difficulties to find the right solutions. The use of specially selected books makes it possible to have a significant impact on the emotional state of people at the lowest cost.

Color Therapy is based on the fact that each of the biologically active zones of the body responds to one of the colors. Exposure to a certain colour removes the energy block that causes the functional disorder. There are no "useful" and "harmful" colors. What is important is the human condition on which the perception of this or that color is superimposed.

\section{CONCLUSION}

Art therapy is a natural, ancient form of change in psychological and emotional state, which is used by many (consciously or not) to relieve mental tension, focus and to calm down. You don't have to be an artist for this - it's enough to take a pen, pencil or paint and start painting. Art therapy belongs to the role of a natural guide to symptoms or experiences, and all this is independent of gender age, feelings of illness, experiences.

Nowadays, art therapy is becoming more and more popular. Creating something, a person expresses his fears and problems on paper or other materials. Methods of art therapy refer to the projective methods and are the removal to the outside world of what we are particularly worried about.

There is no doubt that even in the age of developed medicine one cannot cope with the problem only with traditional treatments: for the body - with mixtures and procedures, and for the soul - with antidepressants. The approach to solving problems should be integrated, because the body is inseparable from the soul, and the soul from the body. Art therapy is, above all, an integral medicine, without age restrictions and side effects. In my opinion, art therapy is a very progressive direction. Using the knowledge of related sciences as a supplement to the canvas of creativity, art therapy will gradually take its rightful place among other therapeutic methods.

\section{REFERENCES}

1. Farokhi M. (2011). Art therapy in humanistic psychiatry. Procedia - Social and Behavioral Sciences.

2. Stuckey H.L., Nobel J. (2010). The connection between art, healing, and public health: a review of current literature. Am J Public Health.

3. https://www.internationalarttherapy.org/

4. http://www.atwb.org./ 